Running header: Information search and dishonesty

Version date: 28 April 2020

Peer Behavior Profoundly Influences Dishonesty:

Will Individuals Seek-out Information about Peers' Dishonesty?

Margarita Leib ${ }^{1} \&$ Maurice Schweitzer ${ }^{2}$

${ }^{1}$ University of Amsterdam

${ }^{2}$ Wharton School, University of Pennsylvania

Correspondence: Margarita Leib, m.leib@uva.nl, (0031)205254251; Center for Research in Experimental Economics and political Decision Making, University of Amsterdam, Roetersstraat 11, 1018WB, Amsterdam, The Netherlands. The research was funded by European Research Council (ERC-StG-637915) and the Wharton Behavioral Lab. 


\begin{abstract}
Seeing others engage in unethical behavior helps individuals justify their own unethical actions. In this article, we explore whether and how individuals search for information about others' unethical behavior. Across two financially incentivized studies (total $N=617$ ), participants could search either free (in Study 1) or costly (in Study 2) information about others' behavior. Our findings reveal that individuals are both curious and are significantly influenced by the information they observe. However, individuals do not aggressively seek information about others' unethical behavior, and are very sensitive to the costs to obtain this information. Free information promotes information search, which increases the likelihood that individuals will observe others' unethical behavior and ultimately engage in unethical behavior themselves. When information is costly, individuals are far less likely to search for information, and are subsequently less likely to observe and engage in unethical behavior themselves. In contrast to prior work that has asserted that "sunlight" and greater access to information will curb dishonesty, we find that free access to information about others' transgression may promote, rather than deter, unethical behavior. To curb unethical behavior, however, organizations may not have to shield individuals from learning about others' transgressions; they may merely need to make this information difficult to obtain.
\end{abstract}

Keywords: Behavioral ethics; Justifications; Information search; Dishonesty; Norms 


\section{Peer Behavior Profoundly Influences Dishonesty: \\ Will Individuals Seek-out Information about Peers' Dishonesty?}

Peer behavior exerts a profound influence on ethical decision making, and in particularly, dishonesty. An individual's decision to lie on an expense reports, cheat on a tax return, or engage in wardrobing is heavily influenced by whether their peers engage in such behavior. Learning that one's peers were dishonest provides individuals with the justification to be dishonest as well (e.g., Gino, Ayal, \& Ariely, 2009; Köbis, Van Prooijen, Righetti, \& Van Lange, 2015). Further, people pay close attention to tempting information, which in turn shapes their lies (Hochman, Glöckner, Fiedler, \& Ayal, 2016; Leib, Pittarello, Gordon-Hecker, Shalvi, \& Roskes, 2019; Pittarello, Leib, Gordon-Hecker, \& Shalvi, 2015). Extant research, however, has yet to consider how individuals might search for information that would help them to justify their dishonesty. That is, although the influence of peer behavior is well documented, we know surprisingly little about how individuals choose to learn about their peers' behavior. Do people actively search for information about peers' dishonesty to justify their own? And how does the ability to search for information influence dishonesty?

\section{Searching for Justifications: The Role of Norms}

The opportunity to engage in self-serving dishonesty presents a challenge. On the one hand, individuals are tempted to secure high profits from dishonest acts. On the other, they are keen to maintain a positive self-image and see themselves as good and moral individuals. To balance the competing motivations, people often limit their dishonesty to maintain a moral selfimage (Mazar, Amir, \& Ariely, 2008). Indeed, in a recent meta-analysis, Abeler, Raymond, and Nosenzo (2019) summarized ninety experiments, revealing that people increase their profits by lying by only 23.4 percent of what they could (see similar findings by Gerlach, Teodorescu, \& Hertwig, 2019). 
Information Search and Dishonesty

A key factor in ethical decision-making is self-serving justifications (Schweitzer \& Hsee, 2002). When individuals engage in dishonest acts, they need to justify their actions to

themselves. To do this, individuals often minimize the nature of the violation or the harm caused by their acts (Shalvi, Gino, Barkan, \& Ayal, 2015). As a result, self-serving justifications reduce the threat to one's moral self-image and allow people to engage in profitable dishonest behavior (Mulder, Jordan, \& Rink 2015; Schweitzer \& Hsee, 2002; Shalvi, Dana, Handgraaf, \& De Dreu, 2011). Self-serving justifications can take place before or after the dishonest act is committed. Justifications that occur before the dishonest act help interpret dishonesty as rather excusable, thus reducing the anticipated threat to one's moral self-image. Justifications that occur after the dishonest act consist of compensatory behaviors, aimed to reduce the experienced threat to one's moral self-image (Shalvi et al., 2015).

One justification that often occurs prior to the dishonest act, is exposure to others' ethical rule violations. When people learn that others have violated ethical rules, they are more likely to violate the rules as well (Fosgaard, Hansen, \& Piovesan, 2013; Gächter \& Schulz, 2016; Gino et al., 2009; Gunia, Wang, Huang, Wang, \& Murnighan, 2012; Robert \& Arnab, 2013; Keizer, Lindenberg, \& Steg, 2008; Köbis et al., 2015; Köbis, Troost, Brandt, \& Soraperra, 2019; O’Fallon \& Butterfield, 2012; Welsh, Ellis, Christian, \& Mai, 2014). For example, Köbis and colleagues (2015) had participants engage in a corruption game in which they could bribe a public official. Bribing the public official would unfairly increase the profits of the briber at the expense of another participant in the task. Before making their decision, participants either learned that 'almost everybody' bribed the public official or that 'almost nobody' bribed the public official. Those who learned that 'almost everybody' bribed the official were 2.3 times more likely to bribe than those who learned that 'almost nobody' bribed. Meta-analytical 
Information Search and Dishonesty

evidence further confirms that information about others' dishonesty increases subsequent dishonest behavior (Gerlach et al., 2019).

Whereas prior work has established that learning about others' dishonesty serves as a justification to lie, whether and how people actively search for such information remains an open question. Prior work on willful ignorance suggest that people deliberately avoid learning some types of information. For example, to justify future selfish acts, people often prefer not to know how their actions affect others (Dana, Weber, \& Kuang, 2007; Ehrich \& Irwin, 2005; Grossman \& Van der Weele, 2017; Shalvi, Soraperra, van der Weele, \& Villeval, 2019). For instance, Dana and colleagues (2007) had participants choose between two monetary allocations, A or B. Participants knew that option A resulted in a higher payoff for them than option B. These monetary allocations also had financial consequences for another person, but participants were not informed whether option A or B was better for the other person. Before making their allocation decision, participants could choose whether or not they wanted to learn about the consequences of choosing option A and B for their counterpart. Although acquiring this information was financially costless, only 56 percent of participants chose to be informed. That is, almost half of the participants preferred to remain ignorant about how their decision would affect the other person. This ignorance afforded participants moral "wiggle room" and justification to choose the selfish allocation. Indeed, participants chose the selfish option, A, more often when they could avoid knowing how their choice will affect others, compared to when they could not avoid knowing how their choice will affect others.

Emerging evidence suggests that people may also search for information strategically (Ambühl, 2017; Olekalns, Horan \& Smith, 2014; Smith, Trivers, \& von Hippel, 2017). Smith and colleagues (2017) had participants write a text persuading an independent judge that Mark 
was either a likable or dislikable person. Before writing the text, participants could watch video segments showing Mark engaging in positive, neutral, and negative behaviors. The order in which the videos were presented varied such that half of the participants first saw mostly positive, then neutral, and then mostly negative videos, and the other half first saw mostly negative, then neutral, and then mostly positive videos. Throughout the task, participants could chose to stop watching the videos and move to the writing task. Results revealed that participants stopped watching videos in accordance to their writing goal. Those who had to write a text to persuade another person that Mark was likable stopped watching videos earlier when positive videos appeared first, compared to last in the video sequence. In contrast, those who had to write a text to persuade another person that Mark was dislikable stopped watching videos earlier when negative videos appeared first, compared to last. Further, acquiring information selectively proved to be advantageous. Participants who sampled information in line with their writing goal were more persuasive than those who did not.

Building on these two streams of research: work showing that observing others' dishonesty influence subsequent dishonesty (e.g., Gino et al., 2009; O’Fallon \& Butterfield, 2012), and work revealing that people strategically both avoid and acquire information (Dana et al., 2007; Smith et al., 2017), we postulate that individuals will actively search for information about others' dishonesty to justify their own future profitable, yet dishonest acts. Further, regardless of whether people search for information specifically about others' dishonesty, we expect that observing others' dishonesty will promote their own dishonesty. Taken together, we hypothesize that compared to people who cannot search for information about their peers' behavior, those who (1) can and (2) do search for information, will be more dishonest. 


\section{Overview of Studies}

We study how people (i) search for, and (ii) are affected by information about others' dishonest behavior. Across two financially incentivized studies, participants first learned that they would engage in a computerized die rolling task in which they could increase their earnings by misreporting die roll outcomes. After learning about the task, but before starting it, participants could acquire information about how other participants who engaged in the task had acted. In Study 1, learning about others' behaviors was financially costless. In Study 2, learning about others' behaviors was costly.

Across our studies, participants learned about prior participants' behavior sequentially. That is, if they searched for information, they learned about how prior participants had acted, one prior participant at a time. Between participants, we manipulated the order in which we presented prior participants' behavior. Half of the participants viewed dishonest behavior early in the sequence; and the other half viewed dishonest behavior late in the sequence. Participants could stop searching for information at any point in time and move to the computerized die rolling task. In both studies we measure participants' information search pattern and their dishonesty. We report all measures and manipulations in the main text and the supplementary online materials $(\underline{\mathrm{SOM}})$. Further, the data is available on Open Science Framework.

\section{Method}

\section{Study 1}

We recruited 404 participants for a study in exchange for $\$ 10$ and the opportunity to earn additional payment. The task took about 5 minutes to complete and was the first in a series of unrelated tasks participants completed in an hour long session.

About half of 404 participants $\left(221 ; 77.37 \%\right.$ females; $\left.M_{\text {age }}=19.96, S D_{\text {age }}=1.52\right)$ completed the no information condition. In the no information condition, participants engaged in 
Information Search and Dishonesty

the computerized die rolling task: they observed a die roll presented as a video segment on a computer screen, and were instructed to report the outcome they observed (Kocher, Schudy, \& Spantig, 2017). Participants learned that the higher the outcome they report, the more they would earn; reporting a 1 earns 10 cents, 2 earns 20 cents, 3 earns 30 cents, 4 earns 40 cents, 5 earns 50 cents, and 6 earns 60 cents. Participants engaged in the task five times, and their bonus payment equaled the sum of their five reports.

Behavior in this condition serves two purposes. First, these results serve as our control condition, establishing a benchmark for the prevalence of dishonesty when information about peers' behavior is absent. Second, we used participants' behavior in this condition as the information we presented to subsequent participants in the remaining conditions. In the no information condition, $74.67 \%$ of participants honestly reported the die roll outcome they observed in all five rounds; $25.33 \%$ misreported the die roll outcome at least once ${ }^{1}$.

In addition to the no information control condition, 183 participants $(72.52 \%$ females, $\left.M_{\text {age }}=20.67, S D=2.65\right)$ took part in one of two information search conditions. Our predetermined data collection stopping rule was to collect as many participants as possible during the time allocated to the study in our lab. At the end of the results section of Study 2 we report a sensitivity analysis for the sample sizes obtained in Studies 1 and 2, showing that our samples were sufficient to detect a small to medium effect size.

In our two information search conditions, participants first read the instructions of the computerized die rolling task. Then, they learned that they would be able to see the behavior of other participants who had engaged in the same task. Specifically, each participant decided between (1) learning about the behavior of one person who engaged in the task before, or (2) starting the computerized die rolling task. If a participant chose to learn about the behavior of 
one prior participant, they saw the five die roll outcomes that a prior participant had observed and reported. After learning about the behavior of a prior participant, the focal participant then choose whether to learn about the behavior of a second prior participant or start the computerized die rolling task. If the focal participant chose to start the computerized die rolling task, they moved directly to the task, see Figures $1 \mathrm{~A}$ and 1B. If the focal participant chose to observe information about a second prior participant, they learned about the observed and reported die roll outcomes of a second prior participant and then faced the same decision: to keep searching information or proceed to the computerized die rolling task. We informed participants in the information search conditions that they could observe the behavior of up to 12 prior people in this same, sequential way and that once they started the computerized die rolling task, they would not be able to learn additional information about others' behavior.

To reflect the base-rate of dishonesty in our panel, three out of the twelve (25\%) prior participants presented were dishonest; the remaining nine $(75 \%)$ were honest. That is, if a participant in the information search conditions chose to learn about all twelve prior people, they would observe the same rate of dishonesty as we observed in the no information condition (see SOM for more information about the stimuli, and for an additional pilot in which information was presented as text instead of numbers). 
(A) Task procedure

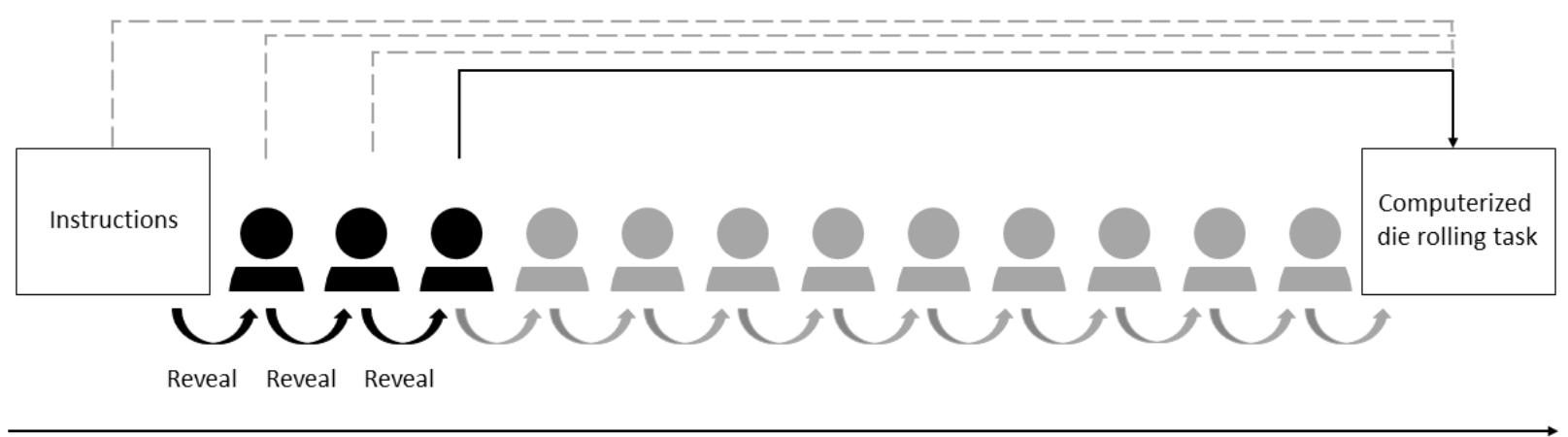

Task progress

(B) Example of the information presented to participants

\begin{tabular}{c|c}
\multicolumn{2}{c}{ Honest } \\
Observed & Reported \\
\hline 5 & 5 \\
2 & 2 \\
6 & 6 \\
5 & 5 \\
3 & 3
\end{tabular}
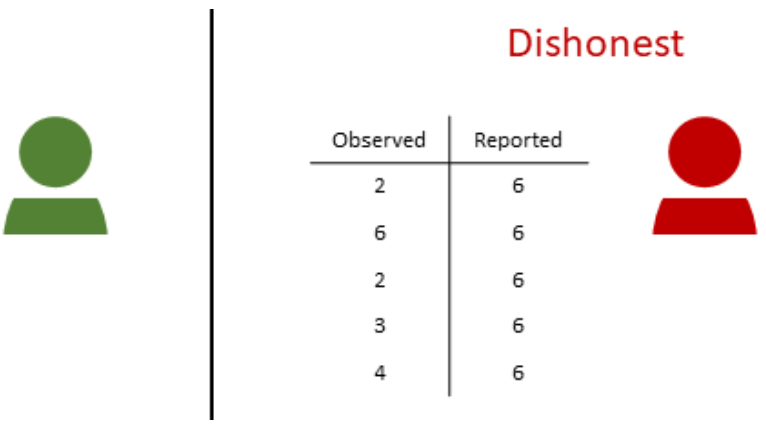

(C) Order of information presented in the early and late dishonesty conditions

Early dishonesty
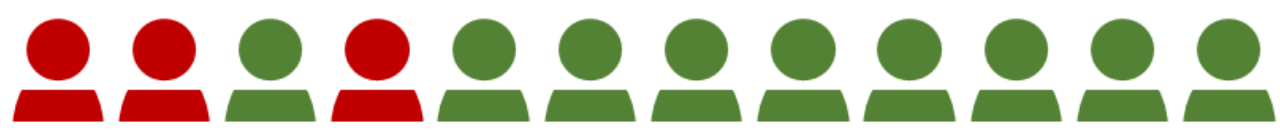

Late dishonesty
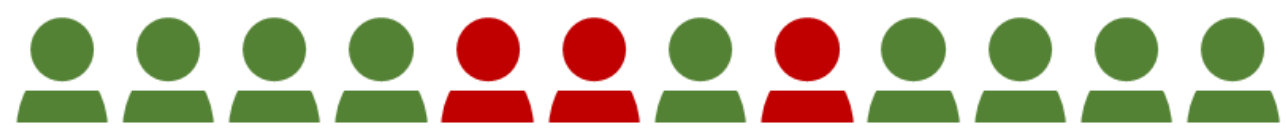

Figure 1. Overview of the procedure. (A) After reading the instructions, participants sequentially chose between either learning about the behavior of a prior person or starting the computerized die rolling task. In the illustration, a participant chose to learn about the behavior of three prior people (in Black), and then moved to the computerized die rolling task. This participant did not observe the behavior of the remaining nine prior people (in Gray). (B) An example of the information presented to participants who learned about a person who reported honestly (in Green) and dishonestly (in Red). If a participant chose to see information about a prior person, they saw the actual ("observed") and reported die roll outcomes of all five rounds that a prior person engaged in. The behavior was not labeled as "honest" or "dishonest" in the stimuli. (C) We manipulated the order of honest (in Green) and dishonest (in Red) behaviors to be either early or late (in the middle) of the information sequence. 
Between participants we manipulated the order in which we displayed the dishonest and honest peers. In the early dishonesty condition, if a participant chose to learn about all twelve prior people, they would see the following order: D, D, H, D, H, H, H, H, H, H, H, H; with "D" representing a person who reported at least one die roll outcome dishonestly, and " $\mathrm{H}$ " representing a person who reported all five die roll outcomes honestly, see Figure 1C. In the late dishonesty condition, the dishonest behavior appeared later in the sequence (in the $5^{\text {th }}, 6^{\text {th }}$, and $8^{\text {th }}$ positions), such that if a participant chose to learn about all twelve behaviors, they would observe the following sequence: H, H, H, H, D, D, H, D, H, H, H, H.

If people indeed actively search for information about others' dishonesty to justify their future behavior, we expect participants to stop searching for information sooner in the early dishonesty than in the late dishonesty condition. If, however, people do not actively search for information about others' dishonesty, we should find that participants stop searching for information about others' behavior similarly in both conditions.

The overall experimental design was a 3 (Information: no information vs. early dishonesty vs. late dishonesty) between-subjects design. After completing the task, for exploratory purposes, we asked participant in the early and late dishonesty conditions to assess how prevalent and justifiable they thought dishonesty is in this study. Further, we asked participants to report the extent to which they thought the information they saw changed their behavior, see SOM for results of these measures.

\section{Results}

Information search. The majority of participants $(n=120,65.57 \%$; more than $50 \%$, Binomial test, $z=4.14, p<.001$ ) chose to learn about the behavior of at least one person who engaged in the task before them. The remaining $34.43 \%$ preferred to start the computerized die 
rolling task without learning any information about others' behavior. Interestingly, the number of peers' behaviors individuals chose to learn about did not differ between the early dishonesty ( $M$ $=2.89, S D=3.47)$ and late dishonesty $(M=2.20, S D=2.70)$ conditions, $b=-0.68, t=-1.48, p=$ .140 , see Figure $2^{2}$. We conducted a Bayesian analysis comparing a model with no predictors to a model that includes condition (early vs. late dishonesty) as a predictor. The analysis revealed a $\mathrm{BF}_{10}=0.44$, suggesting support for the model with no predictors. Our data was 2.25 times more likely to occur when the condition did not predict the number of peers' behaviors searched for, compared to when condition did (see SOM for the same results in a pilot, where information was presented as text).

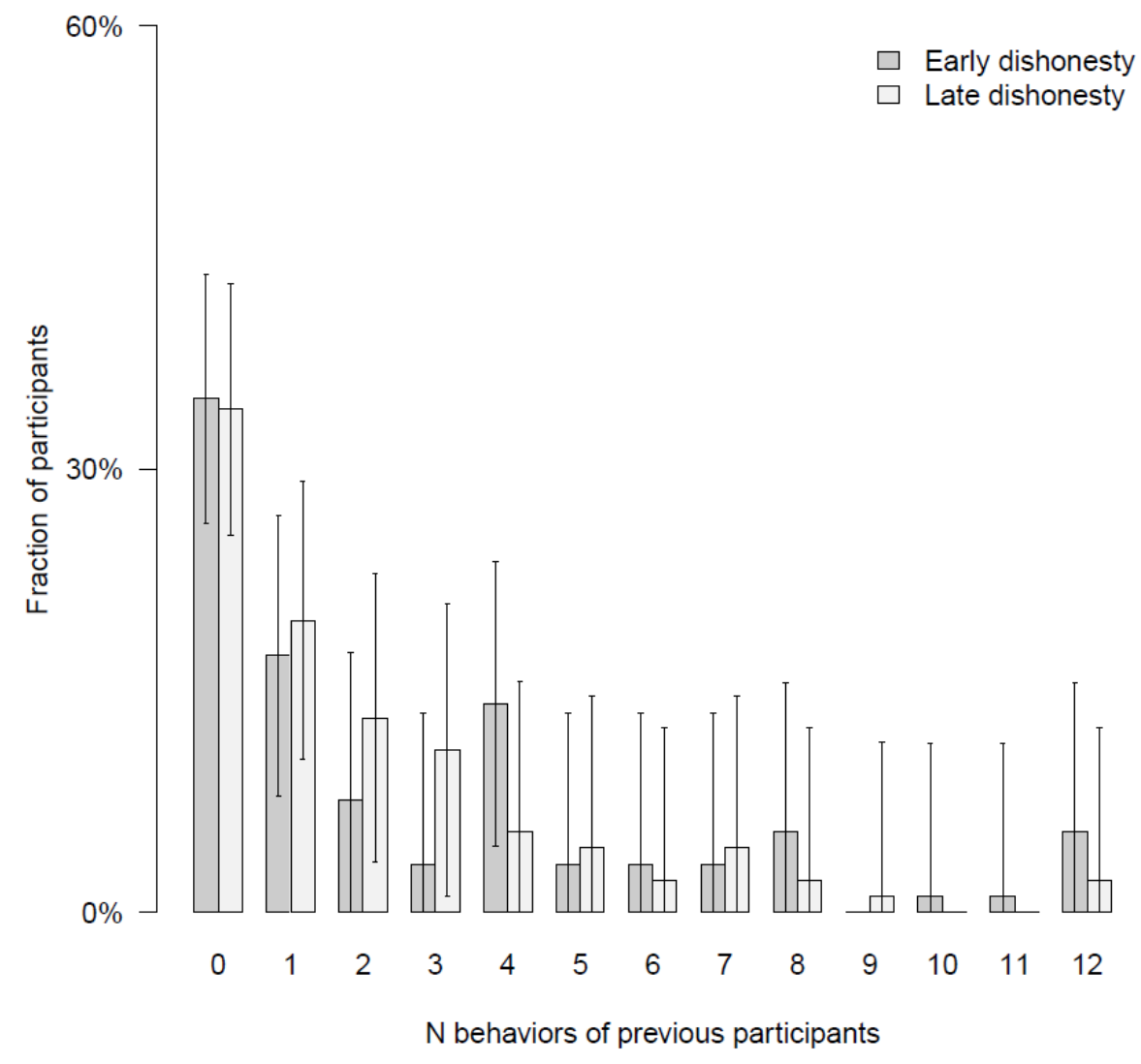

Figure 2. The fraction of participants (and standard error) as a function of condition (early dishonesty vs. late dishonesty) and the number of prior peers' behaviors participants searched for in Study 1. 
Information Search and Dishonesty

Dishonesty. For each participant, we calculate the total amount by which they overclaimed as a measure of level of dishonesty. Specifically, we subtracted the sum of all five die roll outcomes each participant observed from the sum of the five die roll outcomes that participant reported, and then multiplied this number by 10 (cents). We then regressed this amount against the condition (early vs. late dishonesty), whether participants searched for any information (yes vs. no), and the interaction between the two. We found a significant condition $\times$ searching information interaction, $b=-45.00, t=-2.67, p=.008$. Among participants who did not search for information there was no difference between the total amount they over-claimed in the early dishonesty $(M=14.37$ cents, $S D=41.73)$ and late dishonesty $(M=28.70$ cents, $S D=$ 52.96) conditions, $p=.294$. Among participants who searched for information, however, those in the early dishonesty condition claimed more additional pay than those in the late dishonesty condition $(M=56.50$ cents, $S D=65.21$ versus $M=25.83$ cents, $S D=47.91), b=-30.66, t=-$ $3.10, p=.002$, see Figure 3 .

Further, searching for information was associated with participants' over-claims in the early dishonesty condition, but not in the late dishonesty condition. Specifically, among participants in the early dishonesty condition, those who searched for information over-claimed more than those who did not search for information, $b=42.12, t=3.55, p<.001$. We found no difference in over-claims among participants in the late dishonesty condition, regardless of whether they did or did not search for information, $p=.810$. 


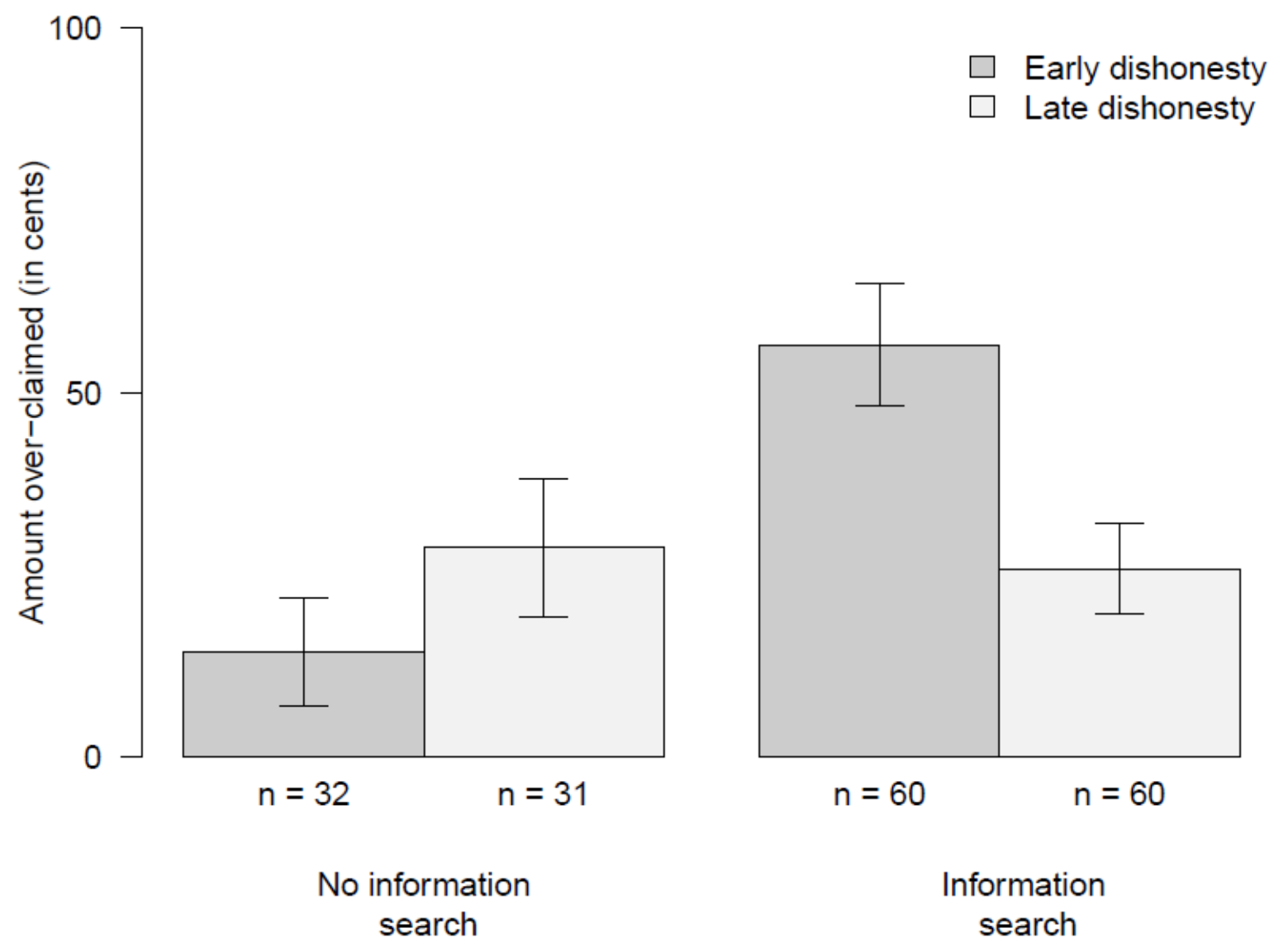

Figure 3. Over-claimed amount (and standard error), in cents, as a function of condition (early vs. late dishonesty) and whether participants searched for information vs. not. The $N$ 's of each group appear below the bar.

Overall, participants were affected by the information they saw. Among participants who searched for information, those in the early dishonesty condition saw more dishonest peers $(M=$ 2.30, $S D=0.86)$, than those in the late dishonesty condition $(M=0.51, S D=0.98), b=-1.78, t=$ $-10.53, p<.001$. The higher number of dishonest peers participants saw was in turn associated with higher rates of over-claiming, see Figure 3. In addition, the correlation between the number of dishonest peers participants saw (between 0 and 3), and their own over-claims was significant, $r=0.323, p<.001$ 
Information Search and Dishonesty

The ability to search for information. Finally, we explore how the ability to search for information affects dishonesty. For that, we compare the amount participants over-claimed in the no information condition to the early dishonesty and late dishonesty conditions, combined, regardless of whether participants searched for information or not. A linear regression analysis revealed that the ability to search for information increased the amount by which participants over-claimed. On average, over-claims were lower in the no information condition $(M=23.71$ cents; $S D=47.31)$ than they were in the early and late dishonesty conditions, combined $(M=$ 34.37 cents, $S D=56.06), b=-10.66, t=-2.07, p=.038$.

\section{Discussion}

Reflecting curiosity about how others behave, a majority of participants searched for some information about peers' behavior. However, participants did not appear to systematically search for evidence for others' dishonesty. Nevertheless, participants did use the information they searched for in a self-serving way. Specifically, participants who observed peers' dishonest behavior, were more dishonest themselves.

Louis Brandeis, a United States Supreme Court Justice, famously declared, that "sunlight is the best disinfectant; electric light the most efficient policeman.” (1914). This guiding principle is consistent with the belief that greater transparency and access to information will deter unethical behavior (Brunetti \& Weder, 2003; Halter, De Arruda, \& Halter, 2009; Starke, Naab, \& Scherer, 2016). In the context of learning about others' dishonesty, however, granting people access to information boosts, rather than deters, dishonesty. Quite possibility, in cases where some people engage in unethical behavior (e.g., tax reporting, insurance claiming), it may be better to make information about others' behavior costly or difficult to access in order to deter dishonesty. 
Information Search and Dishonesty

\section{Study 2}

In Study 2, we extend our investigation to explore how individuals (i) search for, and (ii) are affected by information about others' dishonesty, when it is costly to obtain information.

\section{Method}

A total of 213 participants $\left(68.05 \%\right.$ females, $\left.M_{\text {age }}=20.94, S D=4.95\right)$ took part in Study 2 in exchange for $\$ 10$ and an opportunity to earn additional pay. The task took about 5 minutes to complete and was the first in a series of unrelated tasks in an hour long session. As in Study 1, our aim was to collect as many participants as possible during the time allocated to the study in our lab ${ }^{3}$.

In Study 2, we informed participants that they would engage in a computerized die rolling task, and that before engaging in the task they could learn about the behavior of up to twelve people who engaged in the task before them. All of the instructions and stimuli were identical to Study 1 . The only exception was that in Study 2 participants had to pay 10 cents to observe a prior participant's behavior. That is, after reading the instructions of the task, each participant decided between (1) paying 10 cents and learning about the behavior of one prior person who engaged in the task before, or (2) starting the computerized die rolling task.

This cost was substantial, but less than the expected bonus payment for an honest participant. An honest and very curious participant could earn 175 cents from the die rolling task (3.5 [expected value of a die roll outcome] $\times 5$ [rounds paid] $\times 10$ [cents]), and pay 120 cents for learning about all prior behaviors $(12$ [behaviors] $\times 10$ [cents]). Thus, such a participant would earn on average 55 cents (175-120) on top of the $\$ 10$ show up free.

As in Study 1, between subjects we manipulated the order in which information about (dis)honest behavior was displayed. Thus, the overall experimental design was a 2 (Information: 
Information Search and Dishonesty

early dishonesty vs. late dishonesty) between subject design. Finally, as in Study 1, after completing the task, participants evaluated how prevalent and justifiable they thought dishonesty is, and the extent to which the information they saw changed their intended behavior, see SOM.

\section{Results}

Information search. A minority of participants $(n=47,22.07 \%$; less than $50 \%$, Binomial test, $z=-8.08, p<.001$ ) chose to learn about the behavior of at least one person who engaged in the task before them. The remaining $77.93 \%$ started the computerized die rolling task without learning about others' behavior. Costly information deterred information search. Further, the number of peers' behaviors that participants chose to learn about did not differ between the early dishonesty $(M=0.37, S D=1.28)$ and late dishonesty $(M=0.32, S D=0.65)$ conditions, $b=$ $-0.05, t=-.36, p=.718^{4}$. We conducted a Bayesian analysis comparing a model with no predictors to a model that includes condition (early vs. late dishonesty) as a predictor. The analysis revealed a $\mathrm{BF}_{10}=0.16$, suggesting support for the model with no predictors. Our data was 6.29 times more likely to occur when condition did not predict the number of peers' behaviors searched for, compared to when condition did.

Further, a linear regression predicting the number of peers' behaviors participants searched for revealed that participants searched for less information when it was costly $(M=$ $0.35, S D=1.01$; in Study 2$)$ than when it was free $(M=2.55, S D=3.12$; in Study 1$), b=2.19, t$ $=9.69, p<.001$.

Dishonesty. As in Study 1, for each participant we calculated the amount by which they over-claimed as a measure of dishonesty. We further accounted for the amount participants paid for the information they searched for. For example, a participant who observed five die roll outcomes summing up to 19 , reported a total of five die roll outcomes summing up to 30 , and 
searched for information about the behavior of 2 prior people, over-claimed by 90 cents [(30-192) $\times 10$ cents]. We also conducted the same analyses without accounting for the cost of information search and find the same results, see SOM.

A linear regression predicting participants' over-claiming as a function of the condition (early dishonesty vs. late dishonesty), whether participants searched for information (yes vs. no), and the interaction between the two, revealed a significant condition $\times$ searching interaction, $b=$ $-70.57, t=-4.24, p<.001$. Among participants who did not search for information there was no difference between the over-claims in the early dishonesty $(M=23.69$ cents, $S D=47.94)$ and late dishonesty $(M=26.46$ cents, $S D=52.45)$ conditions, $p=.722$. Among participants who searched for information, those in the early dishonesty condition over-claimed more than those in the late dishonesty condition $(M=65.00$ cents, $S D=68.43$ versus $M=-2.80$ cents, $S D=25.25)$, $b=-67.80, t=-4.61, p<.001$, see Figure 4.

Further, searching for information was associated with participants' over-claiming. Among participants in the early dishonesty condition, those who searched for information overclaimed more than those who did not search for information, $b=41.31, t=3.43, p<.001$. Among participants in the late dishonesty condition, those who searched for information overclaimed less than those who did not search for information, $b=-29.26, t=-2.55, p=.011$. The effect of information search (yes vs. no) on over-claims in the late dishonesty condition is driven by the fact that participants who searched for information, paid for information more than they over-claimed. This effect becomes non-significant, like in Study 1, when we do not account for the cost of information search, see SOM and Figure S1. 


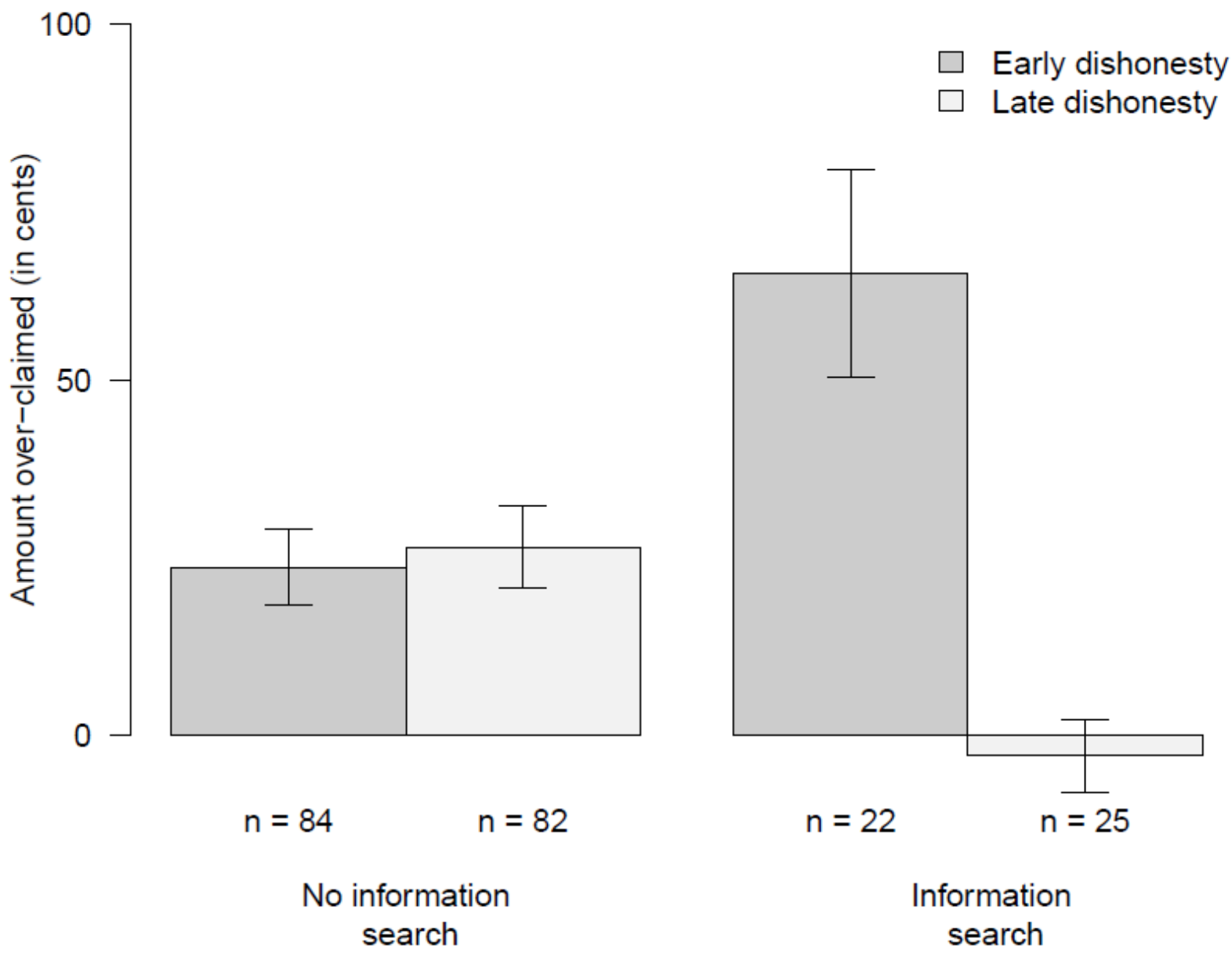

Figure 4. Over-claimed amount (and standard error), in cents, as a function of condition (early vs. late dishonesty) and whether participants searched for information vs. not. The mean in the "information search, late dishonesty" condition is below zero, indicating that on average, participants in this condition paid higher amounts to search for information about others' behavior than they earned by misreporting. The Ns of each group appear below the bar.

As in Study 1, participants were affected by the information they saw. Most $(90.9 \% ; 20$ out of 22) of participants who searched for information in the early dishonesty condition searched for up to two peers' behaviors, and thus only saw dishonest peers. All $(100 \%, 25$ out of 25) of participants who searched for information in the late dishonesty condition searched for up to three peers' behaviors, and thus only saw honest peers. Overall, participants who searched for 
Information Search and Dishonesty

information in the early dishonesty condition saw more dishonest peers $(M=1.36 ; S D=0.58)$ than those in the late dishonest condition $(M=.00, S D=.00), b=-1.36, t=-11.75, p<.001$. The higher number of dishonest peers participants saw was in turn associated with higher rates of over-claiming, see Figure 4. In addition, the correlation between the number of dishonest peers participants saw (between 0 and 3), and their own over-claims was significant, $r=0.162, p=$ .017 .

The ability to search for information. Finally, we compare the over-claims when participants could not search for information (in the no information condition), to when they could, and information was (1) free (in Study 1), and (2) costly (in Study 2). A regression analysis revealed that compared to having no ability to search for information $(M=23.71$ cents, $S D=47.31)$, costly information leads to similar over-claims $(M=25.91$ cents, $S D=52.39), b=$ $2.20, t=0.44, p=.657$. When information was free, however, over-claims were higher $(M=$ 34.37 cents, $S D=56.06), b=10.66, t=5.17, p=.039$.

Sensitivity analysis. We conducted sensitivity analyses to make sure we had sufficient power to detect an effect of condition (early dishonesty vs. late dishonesty) on the information search pattern in Study 1 and 2. Sensitivity analyses for a t-test with $80 \%$ power to detect an effect and significance level of .05 revealed that the sample sizes of Study 1 and 2 ( $n=183$ and $n$ $=213$, respectively) were sufficient to detect a small to medium effect sizes $(d=0.42$ and $d=$ 0.38 , respectively). Further, we conducted sensitivity analyses to make sure we had sufficient power to detect the effect of ability to search for information on dishonesty. Sensitivity analyses for a t-test with $80 \%$ power to detect an effect and significance level of .05 revealed that the sample sizes of the no information $(n=221)$, free information $(n=183)$ and costly information 
$(n=213)$ settings were sufficient to detect a small to medium effect sizes $(d=0.28$ and $d=0.27$, respectively).

\section{Discussion}

As in Study 1, we find that participants do not systematically search for information about others' dishonesty, but are significantly affected by the information they observe. Specifically, participants searched for similar amounts of peers' behavior in the early and late dishonesty condition, but because they observed different behaviors they over-claimed by higher amounts when they observed dishonest peers than when they observed honest peers.

We further find that the cost of information search impacted dishonesty. When information search was costly (Study 2), fewer participants searched for information than when it was free (Study 1), and this difference in turn impacted overall dishonesty. Fewer participants observed dishonest peers in Study 2 than they did in Study 1. As a result, dishonesty in Study 2 was low and similar to a setting where information was not available. Free information (in Study 1) resulted in higher dishonesty.

\section{General Discussion}

Self-serving justifications enable individuals to both profit from dishonesty and maintain a moral self-image. Learning that others have engaged in similar dishonest behavior facilitates this justification process. That is, knowing that others have engaged in similar, unethical behavior helps people preserve their moral self-image (Gino et al., 2009; Köbis et al., 2015; 2019;

O’Fallon \& Butterfield, 2012). In contrast to prior work that has confronted participants with information about others' dishonesty, we examine how people search for information about others' dishonesty. In two financially incentivized studies, we find that people use information they observe to guide their ethical decision making, but that they do not aggressively search for 
information that might facilitate self-serving justifications. Interestingly, participants searched for information about others' behavior to similar extents when information about dishonest others appeared early or late in the information search sequence.

Our findings also reveal that facilitating information search promoted dishonesty. Even though the base-rate of dishonesty was relatively low in our dataset, participants became significantly more likely to lie when they observed even a small number of prior dishonest acts. When information search was free, participants searched for more information and were more likely to observe a dishonest peer. When information search was costly, but still readily affordable to our participants, participants were significantly less likely to search for information and consequently less likely to observe a dishonest peer. This in turn curbed participants' own dishonesty. That is, adding a cost to information search significantly curtailed unethical behavior.

In line with the famous quote "sunlight is the best disinfectant; electric light the most efficient policeman" (Louis Brandeis, a United States Supreme Court Justice, 1914), prior work has identified that greater access to information and greater transparency are promising tools for curbing unethical behavior (Brunetti \& Weder, 2003; Halter et al., 2009; Starke et al., 2016). In contrast, we find that when it comes to information about others' past behavior - that includes even a low rate of dishonesty — providing access to information can promote, rather than deter, unethical behavior. This is true even though the majority of peers in our sample $(75 \%)$ were honest. We conjecture that two key reasons help to account for why this low incidence of dishonesty did not curb unethical behavior. First, participants do not search broadly. Rather, they search locally and are influenced by the small sample of behaviors they observe. Second, participants are heavily influenced by the dishonest acts they observe. That is, observing 
Information Search and Dishonesty

dishonesty is far more likely to promote dishonesty than observing honesty is to promote honesty. Our findings thus add to the growing literature showing that some social-norm based nudges may have negative outcomes, and thus should be designed with care (Bicchieri \& Dimant, 2019; Bicchieri \& Xiao, 2009). Making information costly, may help policy makers balance competing concerns-providing people with the freedom to access information, while mitigating the harmful effects of broadcasting others' ethical transgressions.

\section{Future directions and limitations}

Although prior work has found that people both avoid (Dana et al., 2007) and acquire (Ambühl, 2017; Smith et al., 2017; Olekalns et al., 2014) information strategically, we do not find evidence for the strategic acquisition of information in the context of ethical decision making. We consider two potential reasons for this. One possibility is that information avoidance and acquisition are context dependent behaviors, and do not extent to ethical decision making. For instance, prior work revealed that people are much less likely to avoid information to become willful ignorant when the default choice is to be informed compared to be not informed (Grossman, 2014). Quite possibly, people do not avoid nor acquire information strategically when facing ethical dilemmas.

A second possibility is that people avoid, but do not acquire information strategically to justify their future behavior. Indeed, prior work on information avoidance has focused on environmental friendly choices (Ehrich \& Irwin, 2005) and pro-social monetary allocations (Dana et al., 2007; Grossman \& Van der Weele, 2017). So far, work on information acquisition, however, has focused on goal-oriented behaviors that do involve an ethical component (e.g., writing a persuasive text, Smith et al., 2017; eating an insect, Ambühl, 2017). Thus, it might be 
that actively searching for information to justify an unethical act no longer feels like a legitimate justification for the act, whereas actively avoiding information does.

Similarly, prior work reveals that lies of omission and commission are used differently (Olekalns et al., 2014; Olekalns \& Smith, 2007). Lies of omission, refrain from telling the truth, are more common than lies of commission, actively telling a lie. Indeed, not providing information is perceived as more legitimate than providing false information (Mazar \& Hawkins, 2015; Pittarello, Rubaltelli \& Motro, 2016; Spranca, Minsk \& Baron, 1991). In line with these results, if actively searching for justifications feels less legitimate than exploiting existent justifications, people might not actively search for information about others' dishonesty to justify their future transgressions. Since people do avoid information in some ethical contexts (Dana et al., 2007), and default settings affect information avoidance patterns (Grossman, 2014), an interesting avenue for future work may involve varying the default about what information participants will learn. Assessing whether, and how people avoid information about others' honesty to justify their future transgressions represents a fruitful avenue for future work.

We also call for future work to explore whether and how people actively search for other types of justifications. For instance, people are more likely to lie if their lies benefit others compared to only themselves (Gino, Ayal, \& Ariely, 2013; Wiltermuth, 2011), and when they collaborate with others, compared to act alone (Cohen, Gunia, Kim-Jun, \& Murnighan, 2009; Conrads, Irlenbusch, Rilke, \& Walkowitz, 2013; Gross, Leib, Offerman, \& Shalvi, 2018; Weisel \& Shalvi, 2015). Due to higher sensitivity to losses compared to gains (Tversky \& Kahneman, 1981; Ritov, Baron, \& Hershey, 1993), people lie more to minimize losses than maximize equal sized gains (Grolleau, Kocher, \& Sutan, 2016; Leib et al., 2019; Schindler \& Pfattheicher, 2017). Further, people are more likely to lie when they feel angry (Yip \& Schweitzer, 2016) or envy 
towards others (Moran \& Schweitzer, 2008). Testing whether people are willing to self-select into potentially negative situations in which they may feel angry, jealous, risk a loss, or have responsibly over others' outcomes as a mean to provide themselves with justifications for lying seems like another fruitful path for future research to explore.

\section{Conclusions}

In tempting situations knowing that others were dishonest helps people to justify their own dishonesty. Although people do not aggressively search for information about others' dishonesty to justify their own, individuals are curious about others' behavior and observing even a small amount of dishonest behavior significantly boosts subsequent dishonesty. When information search is costly, however, people are far less likely to search for information, far less likely to observe others' dishonest behavior, and ultimately far less likely to be influence by others' dishonesty. In cases ranging from tax filing to insurance claims, making information search even mildly costly may help to mitigate dishonesty and in turn foster more ethical environments. 
Information Search and Dishonesty

\section{Footnotes}

1. Overall, 9.5\% $(n=21)$ reported 6 in all five rounds; $11.3 \%(n=25)$ misreported 4 or 5 of the die roll outcomes.

2. A Kolmogorov-Smirnov tests further revealed that the distributions of the number of behaviors participants searched for did not differ between conditions, $p=.256$.

3. See OSF.

4. A Kolmogorov-Smirnov tests further revealed that the distributions of the number of behaviors participants searched for did not differ between conditions, $p \sim=1$. 
Information Search and Dishonesty

\section{References}

Abeler, J., Nosenzo, D., \& Raymond, C. (2019). Preferences for truth telling. Econometrica, 87(4), 1115-1153.

Ambühl, S. (2017). An offer you can't refuse? Incentives change how we inform ourselves and what we believe. CESifo Working Papers 6296, CESifo.

Bicchieri, C., \& Dimant, E. (2019). Nudging with care: the risks and benefits of social information. Public choice, 1-22.

Bicchieri, C., \& Xiao, E. (2009). Do the right thing: but only if others do so. Journal of Behavioral Decision Making, 22, 191-208.

Brandeis, L. (1914), "What Publicity Can Do", in Other People's Money and How the Bankers Use It. New York: Frederick A. Stokes.

Brunetti, A., \& Weder, B. (2003). A free press is bad news for corruption. Journal of Public economics, 87, 1801-1824.

Cohen, T. R., Gunia, B. C., Kim-Jun, S. Y., \& Murnighan, J. K. (2009). Do groups lie more than individuals? Honesty and deception as a function of strategic self-interest. Journal of Experimental Social Psychology, 45(6), 1321-1324.

Conrads, J., Irlenbusch, B., Rilke, R. M., \& Walkowitz, G. (2013). Lying and team incentives. Journal of Economic Psychology, 34, 1-7.

Dana, J., Weber, R. A., \& Kuang, J. X. (2007). Exploiting moral wiggle room: experiments demonstrating an illusory preference for fairness. Economic Theory, 33(1), 67-80.

Ehrich, K. R., \& Irwin, J. R. (2005). Willful ignorance in the request for product attribute information. Journal of Marketing Research, 42(3), 266-277. 
Information Search and Dishonesty

Fosgaard, T. R., Hansen, L. G., \& Piovesan, M. (2013). Separating Will from Grace: An experiment on conformity and awareness in cheating. Journal of Economic Behavior \& Organization, 93, 279-284.

Gächter, S., \& Schulz, J. F. (2016). Intrinsic honesty and the prevalence of rule violations across societies. Nature, 531(7595), 496-499.

Gerlach, P., Teodorescu, K., \& Hertwig, R. (2019). The truth about lies: A meta-analysis on dishonest behavior. Psychological bulletin, 145(1), 1-44.

Gino, F., Ayal, S., \& Ariely, D. (2009). Contagion and differentiation in unethical behavior: The effect of one bad apple on the barrel. Psychological science, 20(3), 393-398.

Gino, F., Ayal, S., \& Ariely, D. (2013). Self-serving altruism? The lure of unethical actions that benefit others. Journal of economic behavior \& organization, 93, 285-292.

Grolleau, G., Kocher, M. G., \& Sutan, A. (2016). Cheating and Loss Aversion: Do People Cheat More to Avoid a Loss? Management Science, 62(12), 3428-3438.

Gross, J., Leib, M., Offerman, T., \& Shalvi, S. (2018). Ethical free riding: When honest people find dishonest partners. Psychological science, 29(12), 1956-1968.

Grossman, Z. (2014). Strategic ignorance and the robustness of social preferences. Management Science, 60(11), 2659-2665.

Grossman, Z., \& Van der Weele, J. J. (2017). Self-image and willful ignorance in social decisions. Journal of the European Economic Association, 15(1), 173-217.

Gunia, B. C., Wang, L., Huang, L. I., Wang, J., \& Murnighan, J. K. (2012). Contemplation and conversation: Subtle influences on moral decision making. Academy of Management Journal, 55(1), 13-33. 
Information Search and Dishonesty

Halter, M. V., De Arruda, M. C. C., \& Halter, R. B. (2009). Transparency to reduce corruption?. Journal of Business Ethics, 84(3), 373.

Hochman, G., Glöckner, A., Fiedler, S., \& Ayal, S. (2016). "I can see it in your eyes”: Biased Processing and Increased Arousal in Dishonest Responses. Journal of Behavioral Decision Making, 29, 322-335.,

Keizer, K., Lindenberg, S., \& Steg, L. (2008). The spreading of disorder. Science, 322(5908), 1681-1685.

Köbis, N. C., Troost, M., Brandt, C. O., \& Soraperra, I. (2019). Social norms of corruption in the field: social nudges on posters can help to reduce bribery. Behavioural Public Policy, 128.

Köbis, N. C., Van Prooijen, J. W., Righetti, F., \& Van Lange, P. A. (2015). “Who doesn't?”The impact of descriptive norms on corruption. PloS one, 10(6), e0131830.

Kocher, M. G., Schudy, S., \& Spantig, L. (2017). I lie? We lie! Why? Experimental evidence on a dishonesty shift in groups. Management Science, 64(9), 3995-4008.

Leib, M., Pittarello, A., Gordon-Hecker, T., Shalvi, S., \& Roskes, M. (2019). Loss framing increases self-serving mistakes (but does not alter attention). Journal of Experimental Social Psychology, 85, 103880.

Mazar, N., \& Hawkins, S. A. (2015). Choice architecture in conflicts of interest: Defaults as physical and psychological barriers to (dis) honesty. Journal of Experimental Social Psychology, 59, 113-117.

Mazar, N., Amir, O., \& Ariely, D. (2008). The dishonesty of honest people: A theory of selfconcept maintenance. Journal of marketing research, 45(6), 633-644. 
Information Search and Dishonesty

Moran, S., \& Schweitzer, M. E. (2008). When better is worse: Envy and the use of deception. Negotiation and Conflict Management Research, 1(1), 3-29.

Mulder, L. B., Jordan, J., \& Rink, F. (2015). The effect of specific and general rules on ethical decisions. Organizational Behavior and Human Decision Processes, 126, 115-129.

O’Fallon, M. J., \& Butterfield, K. D. (2012). The influence of unethical peer behavior on observers' unethical behavior: A social cognitive perspective. Journal of Business Ethics, 109(2), 117-131.

Olekalns, M., \& Smith, P. L. (2007). Loose with the truth: Predicting deception in negotiation. Journal of Business Ethics, 76(2), 225-238.

Olekalns, M., Horan, C. J., \& Smith, P. L. (2014). Maybe it's right, maybe it's wrong: Structural and social determinants of deception in negotiation. Journal of Business Ethics, 122(1), 89-102.

Pittarello, A., Leib, M., Gordon-Hecker, T., \& Shalvi, S. (2015). Justifications shape ethical blind spots. Psychological Science, 26(6), 794-804.

Pittarello, A., Rubaltelli, E., \& Motro, D. (2016). Legitimate lies: The relationship between omission, commission, and cheating. European Journal of Social Psychology, 46(4), 481491.

Ritov, I., Baron, J., \& Hershey, J. C. (1993). Framing effects in the evaluation of multiple risk reduction. Journal of Risk and Uncertainty, 6(2), 145-159.

Robert, I., \& Arnab, M. (2013). Is dishonesty contagious? Economic Inquiry, 51(1), 722-734.

Schindler, S., \& Pfattheicher, S. (2017). The frame of the game: Loss-framing increases dishonest behavior. Journal of Experimental Social Psychology, 69, 172-177. 
Information Search and Dishonesty

Schweitzer, M. E., \& Hsee, C. K. (2002). Stretching the truth: Elastic justification and motivated communication of uncertain information. Journal of Risk and Uncertainty, 25(2), 185 201.

Shalvi, S., Dana, J., Handgraaf, M. J., \& De Dreu, C. K. (2011). Justified ethicality: Observing desired counterfactuals modifies ethical perceptions and behavior. Organizational Behavior and Human Decision Processes, 115(2), 181-190.

Shalvi, S., Gino, F., Barkan, R., \& Ayal, S. (2015). Self-serving justifications: Doing wrong and feeling moral. Current Directions in Psychological Science, 24(2), 125-130.

Shalvi, S., Soraperra, I., van der Weele, J. J., \& Villeval, M. C. (2019). Shooting the Messenger? Supply and Demand in Markets for Willful Ignorance. Tinbergen Institute Discussion Paper 2019-071/I. Available at SSRN.

Smith, M. K., Trivers, R., \& von Hippel, W. (2017). Self-deception facilitates interpersonal persuasion. Journal of Economic Psychology, 63, 93-101.

Spranca, M., Minsk, E., \& Baron, J. (1991). Omission and commission in judgment and choice. Journal of experimental social psychology, 27(1), 76-105.

Starke, C., Naab, T. K., \& Scherer, H. (2016). Free to expose corruption: The impact of media freedom, internet access and governmental online service delivery on corruption. International Journal of Communication, 10, 4702-4722.

Tversky, A., \& Kahneman, D. (1981). The framing of decisions and the psychology of choice. Science, 211, 453-458.

Welsh, D. T., Ellis, A. P., Christian, M. S., \& Mai, K. M. (2014). Building a self-regulatory model of sleep deprivation and deception: The role of caffeine and social influence. Journal of Applied Psychology, 99(6), 1268-1277. 
Information Search and Dishonesty

Wiltermuth, S. S. (2011). Cheating more when the spoils are split. Organizational Behavior and Human Decision Processes, 115(2), 157-168.

Weisel, O., \& Shalvi, S. (2015). The collaborative roots of corruption. Proceedings of the National Academy of Sciences, 112(34), 10651-10656.

Yip, J. A., \& Schweitzer, M. E. (2016). Mad and misleading: Incidental anger promotes deception. Organizational Behavior and Human Decision Processes, 137, 207-217. 